\title{
A new species of Mongolotettix Rehn, 1928 from Henan, China (Orthoptera: Acridoidea, Acrididae)
}

\author{
Xiang-Chu Yin, Li-Li Ji \& Li Dai
}

Yin, X. C., Ji, L. L. \& Dai, L. 2017: A new species of Mongolotettix Rehn, 1928 from Henan, China (Orthoptera: Acridoidea, Acrididae). — Entomol. Fennica 28: 103-106.

A new species of the genus Mongolotettix Rehn, 1928 from Henan, China is described. The new species, Mongolotettix tongbaishanensis Yin, Ji et Dai sp. n. is similar to M. shanxiensis Shi, Liu et Li, 2016, but differs from the latter by shorter tegmina of male, which reach the hind margin of the $6^{\text {th }}$ abdominal tergite, the maximum width of cubital area being 1.2 times wider than the maximum width of the medial area, the prozona of male being 1.5 times longer than the metazona, the tegmina of female being short, extending slightly over the hind margin of the $1^{\text {st }}$ abdominal tergite, the length of tegmina being 2.5 times longer than its maximum width, the epiphallus being wider than high, and the length of the upper ovipositor valve being 4.4 times longer than its maximum width.

X. C. Yin, College of Life Science, Hebei University, Baoding 071002, China; and Northwest Plateau Institute of Biology, Chinese Academy of Sciences, Xining 810008, China; *Corresponding author'se-mail:yxch@hbu.edu.cn

L. L. Ji, College of Life Science, Hebei University, Baoding 071002, China

L. Dai, Shanghai Entomological Museum, Chinese Academy of Sciences, Shanghai, 200032, China

Received 4 November 2016, accepted 2 February 2017

\section{Introduction}

The grasshopper genus Mongolotettix Rehn, 1928 contains 9 species that are distributed in Far Eastern Asian countries of China, Japan, Korea, Mongolia, and Russia (Bolívar 1898, Uvarov 1914, Caudell 1921, Bei-Bienko \& Mishchenko 1951, Chogsomzhav 1974, Li \& Lian 1994, Yin et al. 1996, Wan et al. 1998, Xie \& Li 2000, Yin, Xia et al. 2003, Yin, Zhang et al. 2003, Yin et al. 2004, Kim \& Kim 2005, Huang et al. 2010, Eades et al. 2016, Shi et al. 2016). In the present paper, we describe a new species of the genus from China.

\section{Materials and methods}

Descriptions and measurements were made under a stereomicroscope (Leica M 205 A, LAS V 4.0). The figures were drawn with a Canon 5D Mark II and Adobe Photoshop version 9.0 software.

Both specimens studied are deposited in the Shanghai Entomological Museum (SEM), Chinese Academy of Sciences, Shanghai, 200032, China. 
Table 1. Comparison of Mongolotettix tongbaishanensis Yin, Ji et Dai sp. n. and M. shanxiensis Shi, Liu et Li, 2016.

\begin{tabular}{lll}
\hline Character & M. tongbaihanensis & M. shanxiensis \\
\hline Tegmina of male & $\begin{array}{l}\text { Short, reaching hind margin of } \\
6^{\text {th }} \text { abdominal tergite, maximum } \\
\text { width of cubital area 1.2 times } \\
\text { maximum width of medial area }\end{array}$ & $\begin{array}{l}\text { Long, reaching end of epiproct, } \\
\text { maximum width of cubital area } \\
2.6 \text { times maximum width of } \\
\text { medial area }\end{array}$ \\
& $\begin{array}{l}\text { Prozona 1.5 times longer } \\
\text { than metazona }\end{array}$ & $\begin{array}{l}\text { Prozona 1.3 times longer } \\
\text { than metazona }\end{array}$ \\
Pronotum of male & $\begin{array}{l}\text { Short, extending slightly over } \\
\text { hind margin of } 1^{\text {st }} \text { abdominal } \\
\text { tergite, length 2.5 times }\end{array}$ & $\begin{array}{l}\text { Long, reaching middle of } 2^{\text {nd }} \\
\text { abdominal tergite, } 3.8 \text { times longer } \\
\text { than maximum width }\end{array}$ \\
& maximum width & \\
Epiphallus & Wider than high & Width equal to height \\
Upper ovipositor valve & Length 4.4 times maximum width & Length 3.8 times maximum width \\
\hline
\end{tabular}

\section{Description of Mongolotettix tongbaishanensis Yin, Ji et Dai sp. n. (Fig. 1, Table 1)}

Type material. Holotype $\delta^{\lambda}$ : China, Henan, Tongbaishan $31^{\circ} 52^{\prime} \mathrm{N}, 113^{\circ} 57^{\prime} \mathrm{E}, 13$.VII.1984, Zhang Xiu-Jiang leg. (SEM); Paratype ${ }$ : same locality as holotype, 1.VIII.1984, Wang Huang leg. (SEM). Collected from forest grassland by insect net.

Diagnosis. The new species is similar to $M$. shanxiensis Shi, Liu et Li, 2016. The major differences are listed in Table 1.

Description. Male. Body small (Fig. 1a).

Head. Shorter than pronotum; face oblique in profile; frontal ridge gradually widened toward clypeus (Fig. 1b); antennae 20-segmented, extending distinctly over hind margin of pronotum; eyes oval, vertical diameter of eye 1.4 times longer than horizontal diameter and 1.4 times longer than subocular groove.

Thorax. Pronotum cylindrical, lateral and median keel distinct; frontal margin of disc slightly rounded, caudal margin triangular; median keel cut by typical transversal sulcus behind middle of median keel; lateral keels almost parallel, prozona 1.5 times longer than metazoan. Tegmina long, reaching hind margin of $6^{\text {th }}$ abdominal tergite, apically concave in middle, maximum width of cubital area 1.2 times maximum width of medial area (Fig. 1e). Space narrow between meso- thoracic lobes, internal margin of mesothoracic lobes concave, narrowed in middle (Fig. 1c). Hind femur 5.7 times as long as its maximum width, stridulatory margin of femur with 99 stridulatory pegs; hind tibia with 12 spines in both sides, external apical spine absent. Second metatarsomere shorter than first.

Abdomen. Tympanum on both sides of first abdominal tergite, its width nearly equal to height in middle. Furculae lacking. Cercus conical, long, almost reaching tip of anal tergum, 3.0 times as long as wide at base. Subgenital plate long, acuteshaped in lateral view and triangular from above (Fig. 1f). Width of epiphallus wider than high (Fig. 1d).

Female. Body more robust than in male (Fig. 1g). Antennae ensiform, 18 segmented (Fig. 1j). Vertical diameter of eye 1.7 times longer than horizontal diameter and 1.1 times longer than subocular groove; prozona 1.6 times longer than metazona (Fig. 1h); space between mesothoracic lobes slightly narrow (Fig. 1i); tegmina short, extending slightly over hind margin of $1^{\text {st }}$ abdominal tergite, length 2.5 times as long as wide. Hind femur 4.8 times longer than maximum width. Cercus short, conical, not reaching end of subgenital plate; subgenital plate long, length 2.5 times width (Fig. 1k); upper ovipositor valve long, length 4.4 times maximum width, with small teeth on outer margin.

Colouration. Body brown. Antennae yellow. Pronotum yellowish-brown. Tegmina without a 


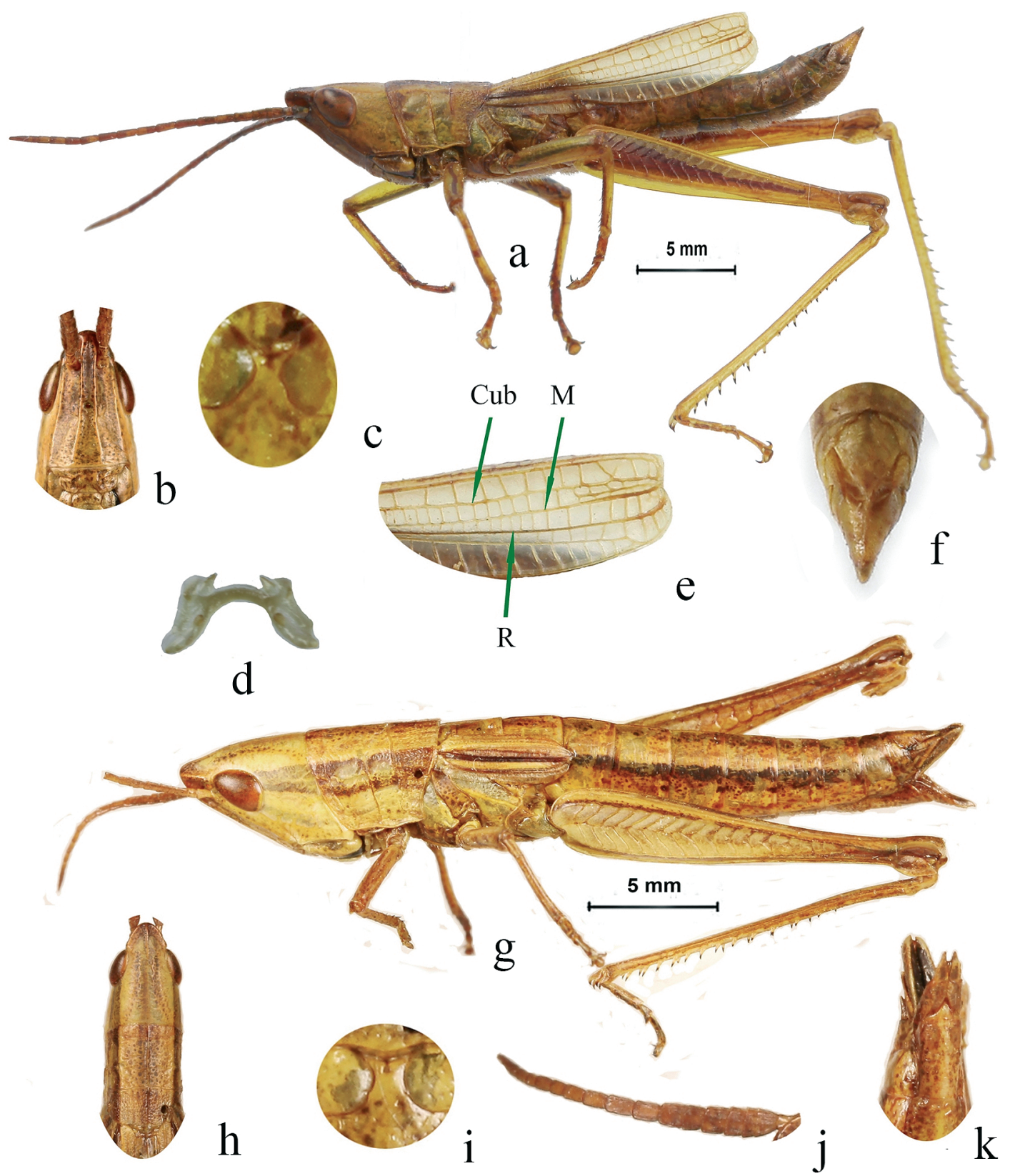

Fig. 1. Mongolotettix tongbaishanensis Yin, Ji et Dai sp. n. - a. Body, $\widehat{\partial}$, lateral view. - b. Head, $\widehat{\jmath}$, front view.

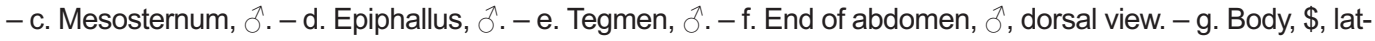
eral view. - h. Head and pronotum,, , dorsal view. - i. Mesosternum, ․ - j. Antenna, ․ - - k. End of abdomen, o, ventral view.

white stripe at base of fore margin in male and with a black longitudinal stripe in middle in female. Abdomen yellowish-brown, with a broad dark longitudinal stripe on both sides. Subgenital plate brown.

Measurements (lengths in mm). Body: $\hat{\sigma}$
20.3, 29.7. Tegmina: $ð 11.4$, $\subsetneq$ 4.4. Hind femur: ㅅ 13.0, ㅇ 15.4 .

Etymology. The description is based on specimens collected from Tongbaishan (Henan, China), which is the type locality of the new species. 
Acknowledgements. This study was funded by the National Natural Science Foundation of China (No. 3137153) and Scientific Research Projects of Hebei Higher Institutions for High-level Personnel (No. GCC2014001. We are grateful to Mr. Zhang Xiu-Jiang and Mr. Wang Huang for collecting the type specimens.

\section{References}

Bei-Bienko, G. J. \& Mishchenko, L. L. 1951: Locusts and Grasshoppers of the U.S.S.R. and Adjacent Countries. No. 40, Part 2. 667 pp.

Bolívar, I. 1898: Contributions a l'etude des Acridiens especes de la faune Indo et Austro-Malaisienne du Museo Civico di storia naturale de Genova. - Annali di Museo Genova, 39 /ser. 2 v. 19, 82.

Caudell, A. N. 1921: Some new Orthoptera from Mokansham, China. - Proceedings of the Entomological Society of Washington 23: 27-35.

Chogsomzhav, L. 1974: A new species of the genus Mongolotettix Rehn, 1928 (Orthoptera: Acrididae) from Mongolia. - Entomological Review 5: 75-77. [In Russian.]

Eades, D. C., Otte, D., Cigliano, M. M. \& Braun, H. 2016: Orthoptera Species File. Version 5.0/5.0. [2016-0812]. [www document]. URL http://Orthoptera.Species File.org. (Site visited on 12 August, 2016)

Huang, Y., Liu, N. \& Lu, H. M. 2010: Research progress in mitochondrial genomes of the Orthoptera insects. Acta Entomologica Sinica 53(5): 581-586.

Kim, T.-W. \& Kim, J.-I. 2005: Taxonomic study of Korean Chrysochraontini (Orthoptera: Acrididae: Gomphocerinae). - Entomological Research 35(2): 101-106.

Li, D. Z. \& Lian, Z. M. 1994: A new species of the genus Mongolotettix Rehn, 1928 (Orthoptera: Acridoidea). — Entomology Research 1: 53-55.
Rehn, J. A. G. 1928: On the relationship of certain new or previously known genera of the Acridine group Chrysochraontes (Orthoptera: Acrididae). - Proceedings of the Academy of Natural Sciences of Philadelphia 80: 185-205, 2 pls.

Shi, J. P., Liu, Z. W. \& Li, B. P. 2016: Two new species and a key to nine species of the genus Mongolotettix Rehn, 1928 from China (Acrididae, Acridoidea, Orthoptera). - Zootaxa 4117(3): 421-428. http://dx.doi.org/ 10.11646/zootaxa.4117.4.9

Uvarov, B. P. 1914: Contributions a la fauna des Orthopteres de la province de Transbaikalie. St. Peternurg. Annals Museum Zoology Academy of Sciences 19: 167-172.

Wan, D. M., Ren, B. Z. \& Zhang, F. L. 1998: A new species of the genus Mongolotettix Rehn, 1928 (Orthoptera: Acridoidea) from Jilin Province. - Acta Zootaxonomica Sinica 23(1): 33-35.

Xie, S. G. \& Li, S. H. 2000: A new species of the genus Mongolotettix Rehn, 1928 (Orthoptera: Acridoidea) from China. - Acta Zootaxonomica Sinica 25(1): 5153.

Yin, H., Li, X. J., Wang, W. Q. \& Yin, X. C. 2004: Inferences about Acridoidea phylogenetic relationship from small subunit nuclear ribosomal DNA sequence. Acta Entomologica Sinica 47(6): 809-814.

Yin, H., Zhang, D. C., Bi, Z. L., Yin, Z., Liu, Y., \& Yin, X. C. 2003: Molecular phylogeny of some species of the Acridoidea based on 16S rDNA. - Acta Genetica Sinica 30(8): 766-772.

Yin, X. C., Shi, J. P., \& Yin, Z. 1996: A synonymic catalogue of grasshoppers and their allies of the world. China Forestry Publishing House, Beijing. 1266 pp.

Yin, X. C., Xia, K. L., Zheng, Z. M., Bi, D. Y., Huang, C. M., You, Q. J., Liu, J. P., Zhang, F. L. \& Li, T. S. 2003 : Fauna Sinica, Insecta, Vol. 32. Orthoptera Acridoidea: Gomphoceridae and Acrididae: 151-157. — Science Publishing House, Beijing. 280 pp. 